\title{
State-of-the-practice and issues surrounding centerline rumble strips
}

\author{
S. J. N. Richards ${ }^{1} \&$ M. Saito ${ }^{2}$ \\ ${ }^{1}$ Hasegawa Engineering, Lethbridge, Alberta, Canada \\ ${ }^{2}$ Civil and Environmental Engineering Department, \\ Brigham Young University, Provo, Utah, USA
}

\begin{abstract}
Centerline rumble strips (CLRSs) are used on two-lane, two-way rural highways for the purpose of reducing cross-over crashes. The state-of-the-practice and issues surrounding CLRSs were reviewed by a literature study, a public opinion survey administered in Utah (533 participants), and a state-of-the-practice survey (41 out of 50 states, Washington DC, and Puerto Rico returned the survey). Installing CLRSs is a low-cost technique for reducing cross-over crashes on two-lane, two-way rural highways. However, the literature review exposed a number of issues associated with CLRSs. The public opinion survey provided statistical evidence supporting the use of CLRSs on two-lane, two-way rural highways. The state-of-the-practice survey compared geometric dimensions of CLRSs with crash data, cost of installation, and maintenance. The survey shows that no geometric standards or highway operating factors have been established for centerline rumble strips. Correlations between the existing installation dimensions and their effectiveness in reducing cross-over accidents, cost of installation, maintenance, and other issues have not been made, indicating the need for clarifying the benefits of CLRSs and minimizing their negative effects. Keywords: centerline rumble strips (CLRSs), driver opinion survey, state-of-the-practice survey, CLRS dimensions, and CLRS warning sign.
\end{abstract}

\section{Introduction}

Cross-over and run-off-the-road crashes are a significant concern among traffic engineers in the United States and around the world. A cross-over crash occurs when a vehicle crosses over the centerline of a two-way highway and collides 
with another vehicle. There are multiple potential causes for these types of crashes. The most common reasons include driver drowsiness, fatigue, and inattention. Installing rumble strips is an increasingly common technique used to combat these causes.

A rumble strip is a series of pavement indentations or protrusions located at a specific boundary of a road, such as a highway shoulder or another lane of traffic. If a vehicle breaches this boundary, it will drive onto the rumble strips. As a vehicle drives across the rumble strips, the tires rise and fall with the pavement profile. The closely spaced intervals of the rumble strips and the oscillating motion of the tires create vibrations and sounds that a vehicle's occupants can feel and hear.

Shoulder rumble strips (SRSs) similar to those illustrated in Figure 1 have been installed on numerous highway shoulders throughout the United States. The success of SRSs inspired the centerline rumble strip (CLRS) concept. As indicated by the name, CLRSs are located along the centerline of an undivided, two-way highway, as shown in Figure 2. The primary purpose of CLRSs is to reduce and prevent cross-over crashes that occur on undivided, two-way highways by providing an audible, vibratory warning to drivers.

US Highway 6 in Utah is notorious for crash-related injuries and fatalities. In response to the number of cross-over crashes on this highway, the Utah Department of Transportation (UDOT) has installed a total of 30 miles of CLRSs along US 6 at four separate locations. Accompanying these installations, UDOT requested an in-depth analysis on the effectiveness of CLRSs and the state-ofthe-practice and issues surrounding CLRSs.

This paper presents the results of a literature survey, a public opinion survey, and a survey among departments of transportation to identify the state-of-thepractice of CLRSs and issues for further improvements in the design of CLRSs.

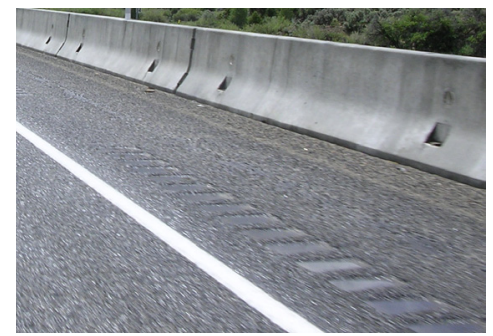

Figure 1: Shoulder rumble strips on US Highway 6 (Photo by Richards).

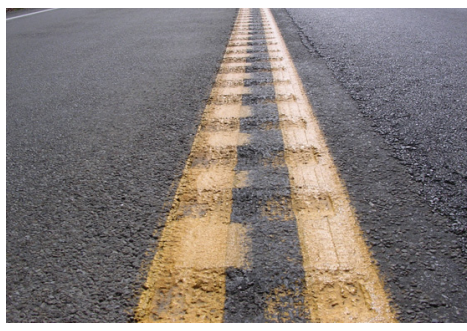

Figure 2: CLRSs on US Highway 6 (Photo by Richards).

\section{Data collection}

As mentioned previously, three methods were used to acquire data: a literature search, a public opinion survey, and a state-of-the-practice survey. The purpose of the literature review was to discover the benefits and issues associated with 
CLRSs. Specific topics for the literature search included safety improvements, cost of installation and maintenance, methods of research, and operational improvements.

The purpose of an anonymous public opinion survey was to discover if the drivers on Utah's undivided highways were for or against future installations of CLRSs. The survey consisted of 23 questions [1] asking about driver demographics; effectiveness of CLRS road-signs; drivers' behavioral reactions to CLRSs; lane visibility, demarcation, and delineation; reaction times to CLRSs; vehicle control; collision reduction; and future installation of CLRSs. Four gas stations and a state-owned rest area in the study area were used to conduct the public opinion survey. A total of 533 surveys were collected. The SAS statistical analysis program [2] was used to determine descriptive statistics and Chi-square tests. The objective of the descriptive analysis was to analyze all 533 surveys to see if there was a general consensus among drivers concerning CLRSs. The objective of the Chi-square tests was to determine if there might be a specific group of people who are directly affected by CLRSs that might be overshadowed by the results of the entire survey. The Chi-square test was performed to investigate certain aspects of CLRSs that have a greater impact on a particular group than on the sample population.

At the time of this study (years 2004 and 2005), CLRSs had not been standardized by any government authority. As a result, a state-of-the-practice survey was designed to compile information about the various technical elements of CLRSs [1]. The survey was subdivided into seven categories: (a) Contact information for the responding agency; (b) status; (c) types and dimensions; (d) highway geometry and operations; (e) costs, noise generation, and control; (f) crash reduction; and (g) safety.

In early November 2004, the state-of-the-practice survey was mailed to all 50 state departments of transportation (DOTs), as well as the District of Columbia DOT and the Puerto Rico DOT. By the end of February 2005, 41 surveys were returned in either paper or electronic form. The next section presents a brief summary of the findings from our three data sets.

\section{State-of-the-practice and issues surrounding CLRSs}

This section of the report discusses the level of usage, mileage, and application of CLRSs; the geometric dimensions of the rumble strips; influential highway geometry; and operations affecting CLRS installation, summarized from our state-of-the-practice survey.

\subsection{Usage}

Predating this study, the latest information on the status of CLRSs was from a report by the Massachusetts Highway Department (MHD). The MHD report identified 20 states and one Canadian province using CLRSs [3]. The recently published NCHRP Synthesis 339: Centerline Rumble Strips reported 22 states and two Canadian provinces that use CLRSs [4]. These numbers resulted from a 
survey with a $90 \%$ response rate and indicate a slight increase in the number of DOTs that use CLRSs in a 2-year period between the releases of these reports. The results of the state-of-the-practice survey supported this later number. According to our survey, the mileage of CLRSs installed in the United States totaled $3846.0 \mathrm{~km}$ as of February 1,2005. The total number of kilometers on two-lane, two-way rural highways is $3511.5 \mathrm{~km}$. There are $334.5 \mathrm{~km}$ of CLRSs on multilane highways, defined as having at least four total lanes.

The United States is not the only country that uses CLRSs. For example, there have been extensive studies on CLRS in Japan by the Civil Engineering Research Institute of Hokkaido (CERIH) [5-7]. CLRSs were installed on 26 roads in Hokkaido, and the total length as of June 2005 was $270 \mathrm{~km}$ [6].

\subsection{Centerline rumble strip type and geometry}

The dimensions of CLRSs have not been standardized as of the time of this study. Thus, there is a variety of dimensions used among the state DOTs. The measurable dimensions - such as the length, width, and depth of CLRSsobtained by the state-of-the-practice survey vary among DOTs as shown in Table 1 .

Table 1: $\quad$ State-of-the-practice survey, CLRS dimensions [1].

\begin{tabular}{|l|cccc|}
\hline \multicolumn{1}{|c|}{ Dimension } & Maximum & Minimum & Mode & Average \\
\hline Length $(\mathrm{mm})$ & 203.2 & 127.0 & 177.8 & 175.3 \\
Width $(\mathrm{mm})$ & 609.6 & 152.4 & 406.4 & 366.3 \\
Depth $(\mathrm{mm})$ & 15.6 & 8.0 & 12.7 & 12.1 \\
Spacing $(\mathrm{mm})$ & 609.6 & 304.8 & 304.8 & 388.5 \\
\hline
\end{tabular}

Similar dimensions are reported by the CERIH of Japan [7]: length $150 \mathrm{~mm}$, width $350 \mathrm{~mm}$, depth $12 \mathrm{~mm}$, and spacing $300 \mathrm{~mm}$.

The results of the state-of-the-practice survey show that most CLRSs are milled installations. A variety of potential milled rumble strip shapes were indicated in the survey. All of the milled rumble strips have a plan-view rectangular shape. The profile shape of the milled rumble strip is concave. Alternatively, a few states use raised-profile rumble strips. These are circular or rectangular in shape, depending on the manufacturer, and have a convex shape against the pavement profile. Currently, the shape of the rumble strip is determined by the type of installation process.

There are three different types of rumble strips that have previously been or are currently being used: milled, rolled, and formed [8]. However, rolled and formed rumble strips have no published record of use as CLRSs.

In an effort to understand the effects of CLRSs on vehicles and drivers, DOTs have conducted field tests that compare various dimensions. For example, the Kansas DOT tested decibel levels [4] and CLRS spacing, and the Japanese compared decibel levels, CLRS depth, and vehicle control [5]. 


\subsection{Highway geometry}

Rumble strip geometry is affected by the accompanying highway geometry. Consequently, the pattern chosen by a transportation agency is typically governed by the existing dimensions of the highway. These dimensions include, but are not limited to, the lane width, cross-section width, and shoulder width. Other considerations are the presence and location of SRSs and available paved median space.

The Pennsylvania CLRS guidelines provide an example of how highway dimensions affect the layout of CLRSs [4]. The criteria for CLRS installation revolve around $3.3 \mathrm{~m}$ lane widths and $0.9 \mathrm{~m}$ shoulders. If the highway geometry is greater than these values, then the Detail \#1 pattern, as shown in Figure 3, is used. Otherwise, Detail \#2 in Figure 3 is used.

The Minnesota DOT has drafted similar guidelines regarding the installation of CLRSs and lane width [4]. Both the Pennsylvania DOT and the Minnesota DOT have a minimum $3.0 \mathrm{~m}$ lane width requirement as outlined in Figure 3 and Table 2 respectively. Both DOTs recommend CLRSs on $3.3 \mathrm{~m}$ and $3.6 \mathrm{~m}$ lanes. Minnesota DOT suggests that if the lanes are $3.0 \mathrm{~m}$ wide, CLRSs are recommended if lane width can be borrowed from the shoulder. Neither DOT recommends CLRS installations on any lane smaller than $3.0 \mathrm{~m}$ wide. Another consideration mentioned by the Minnesota guidelines is the number of lanes. Each potential case for CLRSs is based on two-lane and four-lane highways.

The Missouri DOT recommends the installation of CLRSs based on the roadway cross-section. CLRSs are recommended on widths greater than $7.2 \mathrm{~m}$. Design exceptions are made for roadway widths between $6 \mathrm{~m}$ and $7.2 \mathrm{~m}$ [4]. The lone installation in Delaware is composed of $3.6 \mathrm{~m}$ lanes with $3.0 \mathrm{~m}$ shoulders [9]. The California and Oregon DOTs make no recommendations based on the lane width, cross-section width, or shoulder width [4]. One approach that the Oregon DOT does consider is based upon the available paved median. If a paved median greater than $1.2 \mathrm{~m}$ is available, two rows of rumble strips are installed. Likewise, if less than $1.2 \mathrm{~m}$ is available, one row is installed. If there is no paved median or only a centerline, another layout is used [4].

The highway geometric statistics compiled by our state-of-the-practice survey are summarized in Table 3. Table 3 may appear misleading because four of the six highway dimensions define minimum dimensions, while the second column shows a maximum dimension. The second column entry shows the maximum values for the minimum dimension requirements of the fourth through seventh rows.

Not mentioned in the state-of-the-practice survey is a minimum pavement thickness. The Pennsylvania and Minnesota DOTs use a minimum layer thickness of 2.5 inches. The Missouri DOT recommends a 3.75 -inch minimum layer thickness [4].

\subsection{Highway operations}

Various operational requirements for CLRS installations have been suggested by different states. Design considerations when installing CLRSs include minimum speed, highway volume, passing zones, and signs. 


\begin{tabular}{|l|l|}
\hline \multicolumn{1}{|c|}{ Roadway Description } & \multicolumn{1}{|c|}{ Typical Drawing Detail } \\
\hline $\begin{array}{l}\text { Roadway with } 3.6 \mathrm{~m} \text { or greater lane } \\
\text { width and minimum of } 0.9 \mathrm{~m} \text { of paved } \\
\text { shpulder }\end{array}$ & Detail \#1 \\
\hline $\begin{array}{l}\text { Roadway with } 3.3 \mathrm{~m} \text { lane width and a } \\
\text { minimum of } 0.9 \mathrm{~m} \text { of paved shoulder }\end{array}$ & Detail \#1 or Detail \#2 \\
\hline $\begin{array}{l}\text { Roadway with } 3.3 \mathrm{~m} \text { lane width and less } \\
\text { than } 0.9 \mathrm{~m} \text { of shoulder or no shoulder }\end{array}$ & Detail \#2 \\
\hline $\begin{array}{l}\text { Roadway with } 3.0 \mathrm{~m} \text { lane width with or } \\
\text { without shoulder }\end{array}$ & Detail \#2 \\
\hline $\begin{array}{l}\text { Roadway with less than } 3.0 \mathrm{~m} \text { lane } \\
\text { width }\end{array}$ & $\begin{array}{l}\text { Consult the Bureau of Highway Safety } \\
\text { and Traffic Engineering }\end{array}$ \\
\hline
\end{tabular}

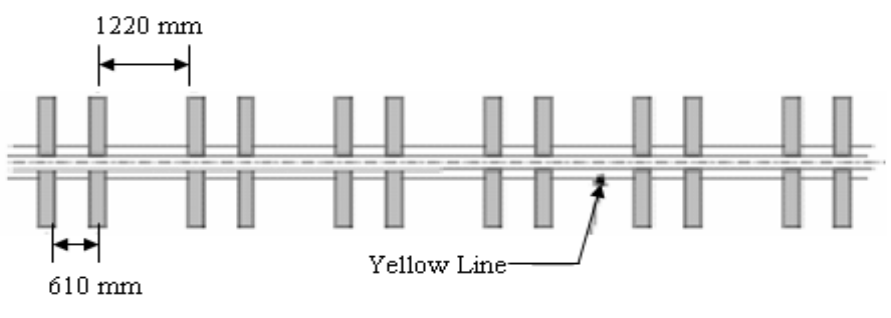

Detail \#1

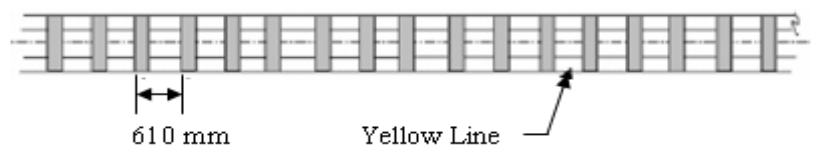

Detail \#2

Figure 3: $\quad$ Pennsylvania patterns for CLRSs [4].

\subsubsection{Speed requirements}

Some DOTs have established minimum design speeds for CLRSs. According to the state-of-the-practice survey and NCHRP Synthesis 339, the minimum speed limits for CLRS installations range from $80 \mathrm{kph}$ to $88 \mathrm{kph}$ [4]. Evidence supporting these minimum speed limit decisions was not found in the literature.

A Pennsylvania study tested mean vehicle speeds when CLRSs were and were not present. The report stated that the CLRS effects "on mean speed and on speed variance were mixed and made it difficult to draw meaningful and accurate conclusions" [10]. A Japanese report stated, "The average speeds on the section with the rumble strips are almost equal on the section without rumble strips" [5]. This report analyzed multiple speeds and multiple rumble strip depths but did not recommend a minimum speed limit. 
Table 2: $\quad$ Minnesota highway geometric considerations for CLRSs [4].

\begin{tabular}{|c|c|}
\hline Roadway Description & CLRS Installation Recommended \\
\hline $\begin{array}{l}\text { 2-lane or 4-lane undivided with } 3.6 \mathrm{~m} \text { or } \\
3.3 \mathrm{~m} \text { lanes, with or without paved } \\
\text { shoulders }\end{array}$ & YES \\
\hline $\begin{array}{l}\text { 2-lane or 4-lane undivided with } 3.0 \mathrm{~m} \\
\text { lanes or less, with or without paved } \\
\text { shoulders }\end{array}$ & $\begin{array}{c}\text { - YES - if min. } 3.0 \mathrm{~m} \text { driving lane can be } \\
\text { maintained by "borrowing" width from the } \\
\text { shoulder, Otherwise NO }\end{array}$ \\
\hline $\begin{array}{l}\text { 2-lane or 4-lane undivided with } 3.0 \mathrm{~m} \text { or } \\
\text { less lanes, without paved shoulders }\end{array}$ & $\mathrm{NO}$ \\
\hline
\end{tabular}

Table 3: $\quad$ State-of-the-practice survey highway geometry statistics [1].

\begin{tabular}{|l|cccc|}
\hline \multicolumn{1}{|c|}{ Highway Dimension } & Maximum & Minimum & Mode & Average \\
\hline Flush Median Width (mm) & 1828.8 & 203.2 & 1219.2 & 955.0 \\
Number of Rows of CLRSs & 2 & 1 & 1 & 1.2 \\
Minimum Lane width (m) & 3.6 & 3.0 & 3.6 & 3.4 \\
Minimum Cross Section Width (m) & 9.0 & 6.0 & N/A & 7.4 \\
Minimum Shoulder Width (m) & 1.8 & 0 & 0.9 & 0.94 \\
Minimum SRS Offset (mm) & 304.8 & 0 & N/A & 116.8 \\
\hline
\end{tabular}

\subsubsection{Lane width requirements}

Lane width requirements may be specified in a state DOT's CLRS guidelines. Reasoning behind minimum lane width requirements was not directly supported in any of the literature found. Some considerations for minimum lane widths may include vehicle tracking on corners, vehicle widths, shoulder width, and right-of-way acquisition.

The Pennsylvania study on lateral vehicle displacement measured the effect of CLRSs in combination with lane widths [10]. CLRSs tend to cause vehicles to laterally displace toward the shoulder. The research recorded significant lateral displacements of vehicles between similar road sections where CLRSs were present and where they were not present. In a study using two lane widths, the wider lane $(3.6 \mathrm{~m})$ had an average displacement of $140 \mathrm{~mm}$ farther from the centerline with CLRSs than without. On the narrower lane $(3.3 \mathrm{~m})$, the displacement was $76 \mathrm{~mm}$ farther from the centerline with CLRSs than without. This report provides evidence of a relationship between CLRSs, drivers, and lane widths. The concept of a minimum lane width when CLRSs are present should be investigated further.

Closely related to a minimum lane width is a minimum cross-section width. Minimum lane width considers drivable space, while minimum cross-section considers the presence of shoulders, paved medians, and multiple lanes. Once 
again, there are some states that have specified minimum cross-section widths for CLRS installations. No evidence of minimum cross-section width and CLRS correlations was discovered in the literature searched.

\subsubsection{Centerline rumble strip road signs}

Three of the questions in our public opinion survey specifically addressed the effects of CLRS road signs. These road signs are located where the CLRS installation begins. An example of CLRS signage is provided in Figure 4. As shown in this figure, a rectangular sign indicating the mileage of the installation generally accompanies the yellow diamond warning sign.

Question 5 in the public opinion survey asked drivers if they had seen the CLRS road sign. The public opinion survey revealed that approximately twothirds of the drivers surveyed recalled having seen the CLRS road sign.

To provide a cross-examination of the survey results, a Chi-square analysis compared the drivers who had seen or observed the road sign with driver demographics. Two inferences were significant at a 95\% confidence level ( $p \leq$ $.05)$. The first inference is that younger drivers are less likely to notice the CLRS road signs. The cell Chi-square values for the "18-25" age row and the "Over 50 " age row are higher than those for the "26-35" and "36-50" age rows. These higher values show a greater deviation between the survey frequency results and the expected results. The frequency results for the "18-25" row and the "No" column are higher than the expected cell value and have a larger cell Chi-square value. This observation allows for the inference that younger drivers are less likely to see the CLRS road signs.

The second inference is that drivers of small vehicles have greater difficulty seeing the CLRS signs. The cell Chi-square for the "Compact Car" row and "No" column is the largest, and the frequency is higher than the expected value. The analysis demonstrates that the drivers of large vehicles are more likely to see the CLRS signage.

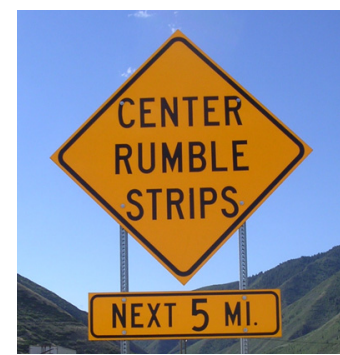

Figure 4: Centerline rumble strip warning sign.

Question 5 of the public opinion survey had a clause in it that prompted survey participants to skip or answer question 5.1. Drivers who had not seen the road sign were prompted to skip this question. Therefore, this question was addressed specifically to those who had seen the signs. Question 5.1 asked if drivers tried to identify the CLRSs after seeing the road sign. The frequency 
analysis shows that the drivers who saw the signs had an increased awareness of the presence of CLRSs. If this is the case, then the signs are beneficial in reducing potential adverse effects caused by confusing CLRSs with SRSs.

Chi-square tables analyzing demographic differences with the CLRS sign effectiveness showed significant probabilities. It was found that female drivers feel stronger about the signs' ineffectiveness than male drivers. Some of the high contribution cells show how fewer young drivers than expected responded after seeing the signs to look for the CLRSs. The middle two groups are neutral in their opinions of the signs. From the same table, the "Over 50" group, which appeared to be the most attentive to the signs, felt the strongest about the ineffectiveness of the signs. Even though the frequency distribution of question 5.1 showed strong support for the effectiveness of CLRS signs to warn about the presence of CLRS (68\% in the "Strongly Agree" and "Agree" groups), various demographic groups felt the signs could be improved.

Question 5.2 is a continuation of the previous two questions. There are two paths to becoming aware of CLRSs on a highway. First, a driver sees the road sign, the sign effectively warns the driver of the CLRSs, and the driver looks for the CLRSs. Second, a driver does not see the sign but recognizes the presence of CLRSs. Most of the drivers believe that CLRSs are easily visible $(82.4 \%$ of the respondents said "Yes" to this question).

Two conclusions may be drawn from the positive response to question 5.2. First, road signs increase drivers' awareness of CLRSs, or, second, CLRSs are visible enough by themselves that signs are not necessary. Despite the implication of the second conclusion, the safer choice is to install CLRS roadsigns. However, other considerations, such as cost or shoulder rumble strip installations, could be included to determine the necessity of the signs.

\section{Conclusions and recommendations}

CLRSs have been studied by a literature review, a public opinion survey, and a state-of-the-practice survey. The literature review of CLRSs revealed that there are advantages and disadvantages to CLRSs. The public opinion survey focused on drivers' views about future installations of CLRSs in Utah. It provided statistical evidence supporting the use of CLRSs on two-lane, two-way rural highways. CLRS road signs also tend to increase driver awareness of CLRSs. The state-of-the-practice survey gathered usage, rumble strip and highway geometrics, cost, and crash data from state DOTs across the United States. National trends in the usage of CLRSs were established.

Research on this topic continues at the time of this writing. Size and layout of CLRSs are not yet uniform nationwide in the United States. A couple of research studies have been conducted to determine optimal size and layout of CLRSs [6,11]. There is still much to be done to standardize the use of CLRSs. Though not mentioned in this paper due to space limitation, other issues surrounding CLRSs, such as noise, pavement deterioration, debris accumulation, and bicycle/motorcycle safety, require further research. 


\section{References}

[1] Saito, M., \& Richards, S.J.N., Evaluation of Four Recent Traffic and Safety Initiatives, Volume III: Centerline Rumble Strips on Rural, TwoWay, Undivided Highways. Utah Department of Transportation, Report No. 05-12, 2005.

[2] SAS Version 9.1.3. SAS Institute Inc., Cary, NC, USA. 2003.

[3] Noyce, D.A., \& Elango, V.V., Safety Evaluation of Centerline Rumble Strips: A Crash and Driver Behavior Analysis. Journal of Transportation Research Board, 1862, pp. 44-53, 2004.

[4] Russell, E.R., \& Rys, M.J., NCHRP Synthesis 339: Centerline Rumble Strips. Transportation Research Board, Washington, D.C., 2005.

[5] Hirasawa, M., Asano, M., \& Saito, K., Introduction of Rumble Strips as a New Safety Improvement Measure against Head-on Collision. Proc. of the $8^{\text {th }}$ Int. Conf. on Applications of Advanced Technologies in Transportation Engineering. Beijing, China, pp. 345-349, 2004.

[6] Hirasawa, M., Takada, T., Asano, M., \& Saito, K., Development of Optimal Centerline Rumble Strips and Evaluating Their Safety Benefits on National Highways in Hokkaido, Japan. $85^{\text {th }}$ Annual Meeting of Transportation Research Board Compendium of Papers. CD-ROM, 2006, 15 pages.

[7] Civil Engineering Research Institute of Hokkaido. Rumble Strips Maintenance Guidelines (Draft). Hokkaido, Japan, June 2006.

[8] Perrilo, K., The Effectiveness and Use of Continuous Shoulder Rumble Strips. Federal Highway Administration. 1998. Available at: http://safety.fhwa.dot.gov/roadway_dept/docs/continuousrumble.pdf. Website last accessed on April 22, 2005.

[9] Delaware Department of Transportation (DelDOT). Centerline Rumble Strips: The Delaware Experience. 2002. Available at: http:/www.deldot.net/static/projects/rumblestrip/handout.pdf. Website last accessed on May 25, 2004.

[10] Porter, R.J., Donnell, E.T., \& Mahoney, K.M., Evaluation of the Effects of Centerline Rumble Strips on Lateral Vehicle Placement and Speed. Journal of Transportation Research Board, 1862, pp. 10-16, 2004.

[11] Dulaski, D.M., \& Noyce, D.A., Development and Evaluation of a Unique Centerline Rumble Strip Pattern to Improve Driver Comprehension. $85^{\text {th }}$ Annual Meeting of Transportation Research Board Compendium of Papers. CD-ROM, 2006, 23 pages. 